\title{
Diagnostic and therapeutic review of cystic parathyroid lesions
}

\author{
Nikolaos Pontikides, ${ }^{1}$ Spyros Karras, ${ }^{1}$ Athina Kaprara, ${ }^{1}$ Angeliki Cheva, ${ }^{2}$ \\ Argyrios Doumas, ${ }^{3}$ Dimitrios Botsios, ${ }^{4}$ Aris Moschidis, ${ }^{5}$ Elias Efthimiou, ${ }^{1}$ \\ John Wass, ${ }^{6}$ Gerasimos E. Krassas ${ }^{1}$
}

${ }^{1}$ Department of Endocrinology, Diabetes and Metabolism "Panagia" General Hospital, ${ }^{2}$ Department of Pathology "Papanikolaou" General Hospital, ${ }^{3} 3^{\text {rd }}$ Department of Nuclear Medicine, "Papageorgiou" General Hospital, ${ }^{4} 4^{\text {th }}$ Department of Surgery, "Papanikolaou" General Hospital, ${ }^{5}$ Department of Surgery, "Panagia" General Hospital, Thessaloniki, Greece, ${ }^{6}$ Department of Endocrinology, Oxford Centre for Diabetes, Endocrinology and Metabolism, Churchill Hospital, University of Oxford, United Kingdom

\begin{abstract}
BACKGROUND: Parathyroid cysts (PC) are uncommon entities in routine clinical practice. The vast majority are nonfunctioning and are commonly present as asymptomatic nodular cervical lesions. PC should be considered in the differential diagnosis of an asymptomatic neck mass. Large PC can manifest with compressive symptoms of the surrounding tissues. OBJECTIVE: The aim of this study is to describe nine new cases of $\mathrm{PC}$ and review the current literature regarding the clinical presentation, the aetiopathology, the diagnostic procedures, as well as the therapeutic approaches for this relatively rare clinical entity. METHODS-PATIENTS: We present nine new patients ( 7 females and 2 males) diagnosed with PC, which in three were ectopic. The diagnosis of PC was based on the elevated levels of PTH in the cysts fluid. Six of the patients had nonfunctioning parathyroid lesions, while the other three had functioning ones. Patients with functioning PC had elevated serum calcium and PTH levels. Five out of nine of the cases had no symptoms, while two patients had compressive symptoms and the other two had signs and symptoms of hypercalcaemia. Needle aspiration (NA) was performed in five out of six patients with nonfunctioning PC. Surgery was the treatment in all three patients with functioning PC. RESULTS: Remission after NA was achieved in four out of five patients with non-functioning PC (follow-up time: $17.7 \pm 2.3$ months). In two of them, two and three aspirations were needed. One patient with nonfunctioning PC submitted to surgery with no previous NA. Patients with functioning PC maintained remission after surgery (mean follow-up time: 22.1 \pm 2.9 months). In one of them, a second surgery was performed due to the co-existence of an ectopic parathyroid adenoma. CONCLUSIONS: The diagnosis of a PC can be established by finding high levels of PTH in the fluid collected by the aspiration of the cyst. PTH and Ca levels in the serum can differentiate functioning from nonfunctioning PC. The treatment of
\end{abstract}


choice in nonfunctioning cysts is aspiration. Surgical removal of the cyst is indicated in hyperfunctioning cysts in cases of relapse after NA in nonfunctioning cysts and when compressive symptoms are present. Based on our series, which appears to be one of the largest reported, we propose a diagnostic algorithm to guide the diagnostic and therapeutic approach to PC.

Key words: Parathyroid cysts, Parathyroid lesions, Hyperparathyroidism, Nonfunctioning, Thyroid nodule

\section{INTRODUCTION}

Parathyroid cysts (PC) were first described in 1880 by Sandstorm, a Swedish anatomist, ${ }^{1}$ but it was Goris, a Belgian surgeon, who first removed a parathyroid cyst from the neck. ${ }^{2}$ Since then, approximately 300 cases have been reported in the literature. ${ }^{3,4} \mathrm{PC}$ are subdivided into functioning and nonfunctioning depending on their ability to secrete PTH or not. Over the past 20 years, we have had the opportunity to diagnose and treat more than 400 cases of primary hyperparathyroidism in an endocrine clinic serving
Northern Greece. In this review we present nine new cases of PC which highlight the clinical heterogeneity of PC and demonstrate their possible clinical manifestations (Table 1).

\section{CASE REPORTS}

\section{A. Nonfunctioning parathyroid cysts}

Long-term remission after needle aspiration

Case 1: A 52-year-old woman was referred suffering from dysphagia and dyspnoea for the past three

Table 1. Demographic, clinical, imaging and biochemical findings of nine patients with parathyroid cysts

\begin{tabular}{|c|c|c|c|c|c|c|c|c|c|}
\hline Case & Sex & Age & $\begin{array}{l}\text { Main } \\
\text { symptoms }\end{array}$ & $\operatorname{Echo}(d / c m)$ & Side & FNA (cc) & $\begin{array}{l}\text { Fluid Ca/ } \\
\text { PTH }\end{array}$ & $\begin{array}{l}\text { Serum } \\
\mathrm{Ca} / \mathrm{PTH}\end{array}$ & Therapeutic result \\
\hline 1 & $\mathrm{~F}$ & 52 & $\begin{array}{l}\text { Dysphagia, } \\
\text { dyspnoea }\end{array}$ & Cystic $(3.4 \times 3.8 \times 3.5)$ & Left & $\begin{array}{l}\text { Watery clear } \\
(11.5)\end{array}$ & $1.22 / 204$ & $1.20 / 58$ & Remission (3 yr) \\
\hline 2 & $\mathrm{~F}$ & 35 & $\begin{array}{l}\text { Painless neck } \\
\text { mass }\end{array}$ & $\begin{array}{l}\text { Hypotense nodule with } \\
\text { cystic degeneration } \\
(3.4 \times 2.9 \times 2.3)\end{array}$ & Left & Watery clear (11) & $-/ 89.6$ & $1.13 /-$ & Remission (9 m) \\
\hline 3 & $\mathrm{~F}$ & 48 & $\begin{array}{l}\text { Incidentally } \\
\text { discovered } \\
\text { extrathyroid } \\
\text { pure cystic mass }\end{array}$ & Cystic $(2.6 \times 1.8 \times 3)$ & Left & Watery clear (8) & $1.07 / 78$ & $1.17 / 28$ & Remission (6 m) \\
\hline 4 & $\mathrm{~F}$ & 49 & $\begin{array}{l}\text { Dysphagia, } \\
\text { dyspnoea }\end{array}$ & Cystic $(6 \times 3.1 \times 2.5)$ & $\begin{array}{l}\text { Partially to } \\
\text { the upper } \\
\text { mediastinum }\end{array}$ & Watery clear (14) & $1.2 / 137$ & $1.19 / 32$ & $\begin{array}{l}\text { Relapses - Surgical } \\
\text { removal }\end{array}$ \\
\hline 5 & $\mathrm{~F}$ & 31 & $\begin{array}{l}\text { Asymptomatic } \\
\text { neck mass }\end{array}$ & Cystic $(4.5 \times 3.5 \times 5)$ & $\begin{array}{l}\text { Left, partially } \\
\text { substernal }\end{array}$ & - & - & - & Total thyroidectomy \\
\hline 6 & $\mathrm{~F}$ & 22 & $\begin{array}{l}\text { Painless neck } \\
\text { mass }\end{array}$ & Cystic $(1.2 \times 2.5 \times 3.1)$ & Left & $\begin{array}{l}\text { Watery clear } \\
(11.5)\end{array}$ & $1.22 / 110$ & $1.10 / 41$ & $\begin{array}{l}\text { Relapse (3 m) } \\
\text { - Aspiration - } \\
\text { Remission (2 yr) }\end{array}$ \\
\hline 7 & M & 82 & $\begin{array}{l}\text { Constipation, } \\
\text { polyouria, } \\
\text { muscle weakness }\end{array}$ & $\begin{array}{l}\text { Cystic }(5.6 \times 4 \times 4.2 \text {, with } \\
\text { multiple echogenic } \\
\text { bodies })\end{array}$ & Right & $\begin{array}{l}\text { Bloody viscous } \\
\text { (14) }\end{array}$ & 1.28 / 899 & $1.48 / 1064$ & $\begin{array}{l}\text { Total removal of } \\
\text { thyroid remnant, } \\
\text { Parathyroidectomy }\end{array}$ \\
\hline 8 & M & 51 & $\begin{array}{l}\text { Polyouria, } \\
\text { polydipsia, } \\
\text { muscle weakness }\end{array}$ & $\begin{array}{l}\text { Partially cystic } \\
(3.3 \times 2.5)\end{array}$ & Right & $\begin{array}{l}\text { Viscous fluid (12), } \\
\text { intraoperatively }\end{array}$ & $\begin{array}{l}1.27 / \\
>2500\end{array}$ & $1.48 / 881$ & $\begin{array}{l}\text { Parathyroidectomy, } \\
\text { Total thyroidectomy } \\
\text { (ectopic adenoma) }\end{array}$ \\
\hline 9 & $\mathrm{~F}$ & 43 & Asymptomatic & $\begin{array}{l}\text { Partially cystic } \\
(4 \times 3.6 \times 2.1)\end{array}$ & Left & - & - & $1.42 / 171$ & Parathyroidectomy \\
\hline
\end{tabular}


years. The physical examination revealed a palpable round-shaped mass in the left thyroid lobe. The ultrasound (US) showed a cystic mass (d: 3.4 x $3.8 \mathrm{x}$ $3.5 \mathrm{~cm}$ ) attached to the left thyroid lobe. A needle aspiration (NA) was performed. The cyst yielded 11.5 cc of a colourless crystal clear fluid. The aspirate's ionized calcium $\left(\mathrm{Ca}^{++}\right)$concentration was normal, while PTH levels were elevated (204 pg/ml, normal serum range $10-65 \mathrm{pg} / \mathrm{ml}$ ). Serum ionized $\mathrm{Ca}^{++}$and PTH levels were normal. Immediately after the aspiration the patient reported relief from obstructive symptoms. The patient remained in remission during long-term follow-up (three years).

\section{Short-term remission after needle aspiration}

Case 2: A 35-year-old woman presented with a painless neck mass. The US revealed a thyroid nodule (d: $3.4 \times 2.9 \times 2.3 \mathrm{~cm})$ with peripheral vascularisation and a large cystic degeneration. A NA was performed which revealed $11 \mathrm{cc}$ of a colourless crystal clear fluid. The aspirate's thyroglobulin (Tg) and PTH concentrations were: $4.1 \mathrm{ng} / \mathrm{ml}$ (almost undetectable) and $89.6 \mathrm{pg} / \mathrm{ml}$, respectively, while serum levels of $\mathrm{Ca}^{++}$ were normal. Nine months later there were no signs of relapse.

Case 3: A 48-year-old woman was diagnosed with a large cystic neck mass during her carotid arteries examination with echo-Doppler. The US of the thyroid revealed a cystic structure (d: $2.6 \times 1.8 \times 3.0 \mathrm{~cm})$ below the left thyroid lobe. A NA was performed which yielded $8 \mathrm{cc}$ of a colourless crystal clear fluid. The aspirate's $\mathrm{Ca}^{++}, \mathrm{Tg}$ and PTH concentrations were: $1.07 \mathrm{mmol} / \mathrm{l}, 3.0 \mathrm{ng} / \mathrm{ml}$ and $78 \mathrm{pg} / \mathrm{ml}$, respectively, while serum levels were $1.17 \mathrm{mmol} / \mathrm{l}, 11 \mathrm{ng} / \mathrm{ml}$ and $28 \mathrm{pg} / \mathrm{ml}$, respectively. Six months later the neck US was normal. No clinical signs of relapse were evident.

\section{Relapses following repeated aspirations}

Case 4: A 49-year-old woman presented with compressive symptoms (dysphagia and dyspnoea) which had started three months before initial evaluation. The US revealed a large cystic mass which partially descended into the upper mediastinum (d: 6.0 x 3.1 x $2.5 \mathrm{~cm}$ ). A NA was performed which yielded 14 cc of a colourless crystal clear fluid. The aspirate's $\mathrm{Ca}^{++}, \mathrm{Tg}$ and PTH concentrations were: $1.2 \mathrm{mmol} / \mathrm{l}$, $3.0 \mathrm{ng} / \mathrm{ml}$ and $137 \mathrm{pg} / \mathrm{ml}$, respectively, while serum levels of $\mathrm{Ca}^{++}$and PTH were normal. Two repeated aspirations four and twelve months later failed to sustain remission and surgical removal of the cyst was performed.

\section{Unexpected histopathologic finding}

Case 5: A 31-year-old woman was admitted to our department with a large (d: $4.5 \times 3.5 \times 5.0 \mathrm{~cm})$ painless and asymptomatic cystic neck mass in the left thyroid lobe with partial substernal extension. The biochemical evaluation showed normal serum thyroid hormone levels. Surgical treatment was suggested and the patient underwent total thyroidectomy. Histopathological examination revealed an intrathyroid pure cystic structure. The internal layer of the cyst consisted mainly of compressed chief parathyroid cells that proved the existence of parathyroid cystic lesion.

\section{Asymptomatic parathyroid cyst: long-term remission after two aspirations}

Case 6: A 22-year-old woman presented with a painless left nodular neck mass with no other local or systemic signs or symptoms. The US showed a well circumscribed (d: $1.2 \times 2.5 \times 3.1 \mathrm{~cm})$ cystic mass, attached to the left thyroid lobe. A NA was performed. The cyst yielded $11.5 \mathrm{cc}$ of a colorless crystal clear fluid. The aspirate's $\mathrm{Ca}^{++}$levels were normal (1.22 $\mathrm{mmol} / \mathrm{l})$, but PTH levels were high $(110 \mathrm{pg} / \mathrm{ml})$, while the patient's serum $\mathrm{Ca}^{++}$and PTH levels were both within the normal range $(1.10 \mathrm{mmol} / \mathrm{l}$ and $41 \mathrm{pg} / \mathrm{ml}$, respectively). Three months later the cystic lesion relapsed and a second aspiration was performed with the same findings. About two years after the second aspiration no clinical or imaging findings of recurrence were documented during the follow-up.

\section{B. Functioning cystic parathyroid lesions}

\section{Cystic parathyroid mass causing severe hyperparathyroidism}

Case 7: An 82-year-old man reported severe constipation, polyuria and proximal muscle weakness of six months' duration. He had a palpable mass in the right side of the neck. The biochemical workup showed severe primary hyperparathyroidism with serum $\mathrm{Ca}^{++}$, phosphorus and PTH levels of $1.48 \mathrm{mmol} / 1,2.1 \mathrm{mg} / \mathrm{dl}$ (normal range $2.8-4.6 \mathrm{mg} / \mathrm{dl}$ ) and $1064 \mathrm{pg} / \mathrm{ml}$ (10-65), respectively (Table 1). A Tc-Sestamibi scintigraphy showed a large hot mass in the anatomical region of the right thyroid lobe. A $21 \mathrm{G}$ FNA was performed which revealed $14 \mathrm{cc}$ of a bloody, viscous aspirate with high $\mathrm{Ca}^{++}$, PTH and Tg levels: $1.28 \mathrm{mmol} / 1,899 \mathrm{pg} /$ 
$\mathrm{ml}$ and $2300 \mathrm{ng} / \mathrm{ml}$, respectively. He was submitted to surgical treatment. Histopathologic findings showed a uniform cell population consisting of parathyroid cells without atypia or mitosis. Two months later the patient was euthyroid with $\mathrm{Ca}^{++}$and PTH levels within the normal range, and was shown to have remained so on the annual re-examination conducted a year after initial diagnosis.

\section{Sustained hyperparathyroidism: successful removal of a second large ectopic substernal hyperfunctioning cystic parathyroid adenoma}

Case 8: A 51-year-old male presented with polyuria, polydipsia and muscle weakness. The biochemical workup revealed hypercalcaemia $(1.48 \mathrm{mmol} / \mathrm{l})$. Further laboratory workup confirmed the diagnosis of primary hyperparathyroidism (elevated PTH levels: $881 \mathrm{pg} / \mathrm{ml}$ ). Tc-Sestamibi scintigraphy findings were consistent with hyperfunctioning parathyroid tissue in the lower part of the right thyroid lobe. The patient underwent parathyroidectomy. Two months after the initial surgery the patient's serum $\mathrm{Ca}^{++}$and PTH levels were again elevated $(1.39 \mathrm{mmol} / \mathrm{l}$ and $489 \mathrm{pg} / \mathrm{ml}$, respectively). Tc-Sestamibi scintigraphy showed a large hot area in the right sternoclavicular region with a decreased initial uptake and a delayed washout after three hours. The suspicious findings of a large hyperfunctioning ectopic adenoma suggested the need for further evaluation via US and computed tomography scan, which revealed an ectopic round shaped tissue $(3.5 \mathrm{~cm})$ with low dense features and a peripheral media contrast uptake in the upper right mediastinum adjacent to the right jugular vein (Figure 1). The patient was submitted to a second successful surgical removal of the mass. Intraoperative PTH levels decreased from 695 to $64 \mathrm{pg} / \mathrm{ml}$ and to $25 \mathrm{pg} /$ $\mathrm{ml}, 10$ and 20 minutes after the surgical excision of the mass. The mass contained a viscous bloody fluid with high PTH $(>2500 \mathrm{pg} / \mathrm{ml})$ and high-normal $\mathrm{Ca}^{++}$ levels $(1.27 \mathrm{mmol} / \mathrm{l})$. The histological findings confirmed the existence of a partially cystic parathyroid adenoma with bloody content.

\section{Partially cystic parathyroid adenoma: successful parathyroidectomy}

Case 9: A 43-year-old woman presented with a case of asymptomatic, moderately severe hyperparathyroidism (serum $\mathrm{Ca}^{++}$and PTH levels $1.42 \mathrm{mmol} / \mathrm{l}$ and $171 \mathrm{pg} / \mathrm{ml}$, respectively). Laboratory evaluation (US,

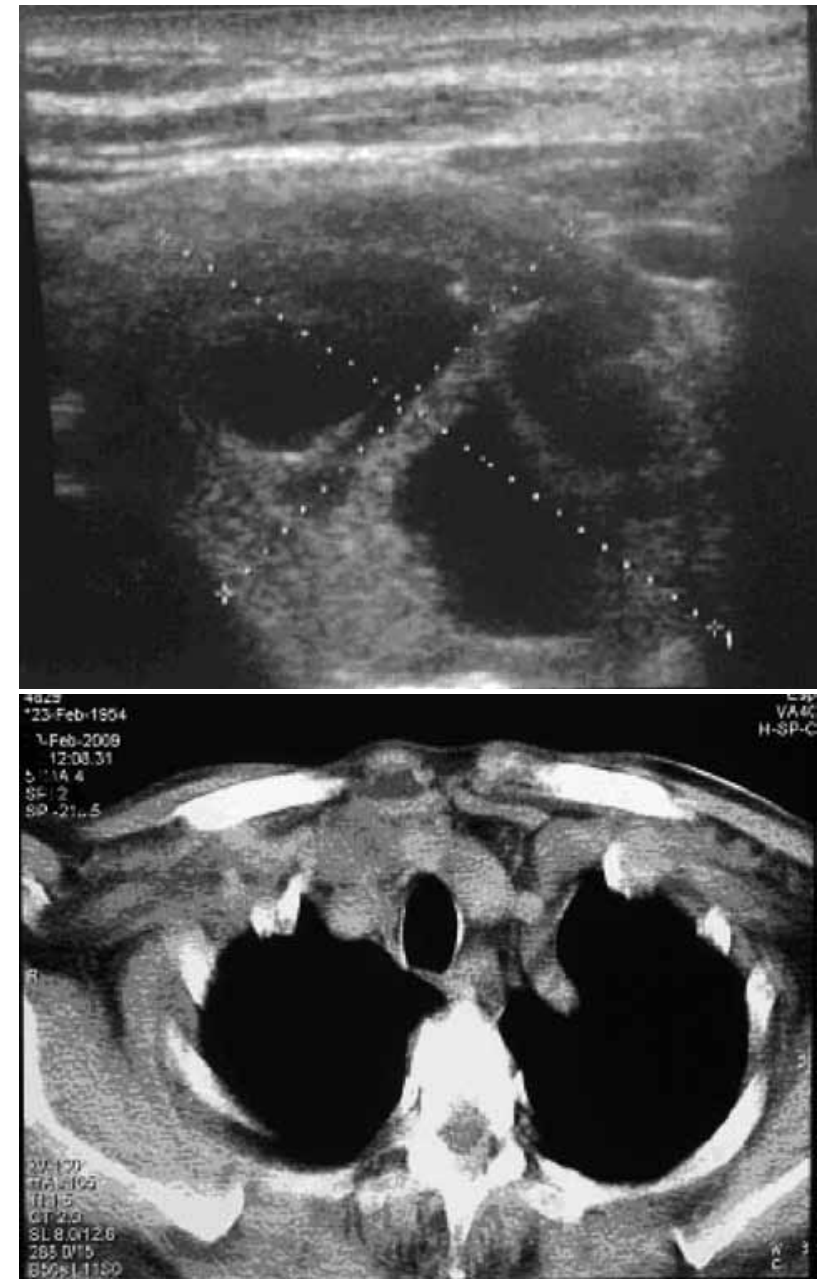

Figure 1. (a) Large mass in the lower right side of the neck, (b) Ectopic round shaped tissue with low dense features and a peripheral media contrast uptake in the upper right mediastinum adjacent to the right jugular vein (Case 8).

Tc-Sestamibi scintigraphy) revealed a large, partially cystic hyperfunctioning parathyroid neoplasm (4.0 x $3.6 \times 2.1 \mathrm{~cm}$ ) to the left inferior parathyroid body. The patient underwent successful surgical removal of the mass with rapid decrease of the intraoperative PTH levels. The histological findings showed a parathyroid adenoma with follicular and microcystic growth pattern with abundant eoshinophilic fluid mimicking colloid material (Figure 2).

\section{DISCUSSION}

\section{General comments}

The incidence of parathyroid cystic lesions var- 
ies among surgical and US studies. With regard to surgical studies, in $2009 \mathrm{McCoy}_{\text {et }} \mathrm{al}^{5}$ reported a 3\% incidence of cystic parathyroid lesions in 1769 patients undergoing parathyroidectomy for primary hyperparathyroidism. However, in a recent retrospective study of 6621 patients submitted to neck US, Cappelli et al ${ }^{6}$ reported a $0.075 \%$ incidence in an unselected population, that is, much lower than previously reported. ${ }^{7,8}$ According to our experience based on more than 400 parathyroidectomies over the last 20 years, the incidence of pure or partially cystic parathyroid lesions, both functioning and nonfunctioning, was about 2.3\% (unpublished data). PC are more common in the aging population, usually occurring in the fourth and fifth decade of life. ${ }^{9-11}$ However, to date several paediatric cases have also been described. ${ }^{12}$
Most pure $\mathrm{PC}$ are orthotopic and solitary and are found more frequently in women. Nevertheless, PC can be ectopic and localized anywhere in the cervical region, including the thyroid (as our fifth case), the mediastinum (as our fourth and eighth cases) and the thymus. ${ }^{13}$

The heterogeneous clinical presentation of PC is determined by their hormonal activity, size and location. Nonfunctioning cysts represent about $80 \%$ of all cases and manifest no hormonal overactivity, ${ }^{10}$ while functioning $\mathrm{PC}$ are found more frequently in men. ${ }^{5}$ Nonfunctioning PC are discovered incidentally during physical or imaging evaluation for other reasons (cases 1 and 4) or after surgical excision of thyroid nodules on histological examination as in our fifth case. Some cases produce local symptoms
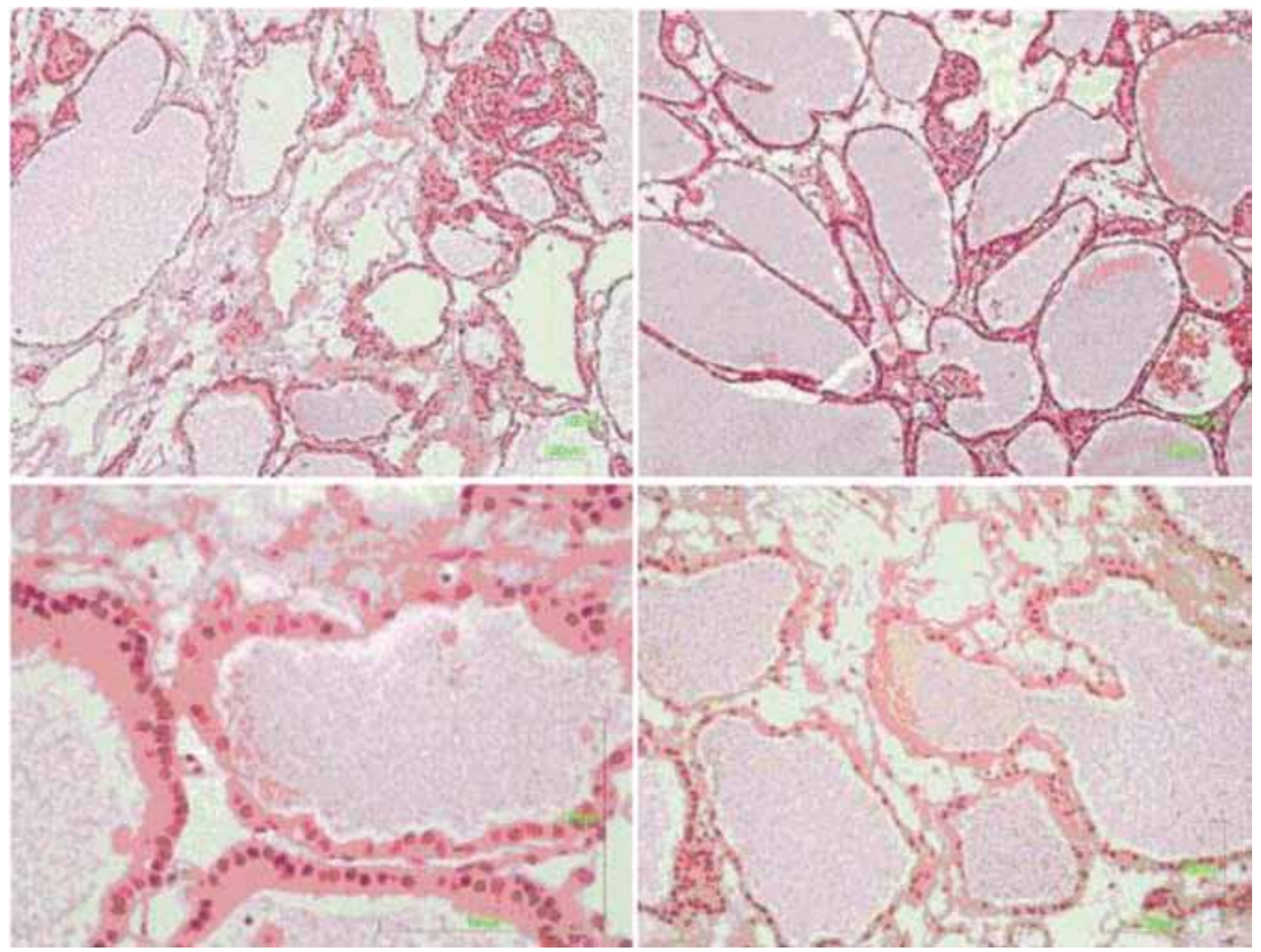

Figure 2. Histopathological findings showed a parathyroid adenoma with follicular and microcystic growth pattern with abundant eoshinophilic fluid mimicking colloid material (Case 9). 
depending on the size and location of the cyst. When large nonfunctioning cysts are localized in the mediastinum they can cause compressive symptoms such as dysphagia and dyspnoea. Mediastinal PC usually represent large structures $(\geq 4 \mathrm{~cm}) .{ }^{14-16}$ Additionally, unusual symptoms, such as vocal cord paralysis due to local compression on recurrent laryngeal nerve, ${ }^{17-19}$ respiratory failure and jugular vein thrombosis due to a large mediastinal nonfunctioning $\mathrm{PC}$, have been described..$^{20}$ Nonfunctioning PC can also be located inside the thyroid where they are discovered as an incidental finding after NA during the evaluation of a multinodular goiter or a solitary thyroid nodule. ${ }^{21-24}$ When a PC extends to the upper mediastinum, it can mimic a retrosternal goiter with or without symptoms of tracheal compression. ${ }^{25}$

The clinical appearance of functioning parathyroid lesions is similar to that of nonfunctioning PC. However, while the clinical symptoms of nonfunctioning cysts are limited mainly to those caused by compression of the adjacent structures, functioning cysts are also related to excessive secretion of PTH (cases 7 and 8). Consequently, apart from the clinical signs related to their location and size, functioning PC can be manifested with signs and symptoms of hyperparathyroidism and malignant hypercalcaemia or even hypercalcaemic crisis. In these cases, signs and symptoms of compression and clinical manifestations of primary hyperparathyroidism can coexist. ${ }^{26-29}$

\section{Pathogenesis}

There are several hypotheses regarding the pathogenesis of PC. It is suggested that nonfunctioning PC are true cysts derived as developmental ontogenic formations, arising from the $3^{\text {rd }}$ and $4^{\text {th }}$ branchial clefts. ${ }^{30}$ The nonfunctioning PC wall on microscopy examination often contains elements of lymphoid, salivary, adipose or thymic tissue, this providing further evidence for this hypothesis. Another hypothesized mechanism of cyst formation is the coalescence of microcysts into macrocysts. Microcysts can occur in the parathyroid gland, possibly as a result of gradual local degeneration of the gland or retention of colloid secretion..$^{10}$ Recently, Lima et al reported that there is often co-expression of $\mathrm{PTH} / \mathrm{PTH}$ related peptide receptor 1 in $\mathrm{PC}$ and the latter can be involved in the proliferation of the lesion. ${ }^{31}$ In addition, the glial cells missing gene $\mathrm{Gcm} 2$ (a regulatory gene of parathyroid development), has been implicated in the pathogenesis of parathyroid neoplasia and may serve as an adjunct predictive marker for the diagnosis of PC. ${ }^{32}$ Functioning $\mathrm{PC}$ are considered to have a different pathogenesis. In a recent study, all functioning PC were histologically identified as the result of cystic degeneration of a preexisting parathyroid adenoma or, rarely, parathyroid carcinoma. ${ }^{5}$

\section{Diagnosis}

The diagnostic workup includes physical examination, neck US, Tc-Sestamibi scintigraphy of the thyroid-parathyroids, computed tomography, magnetic resonance imaging, NA biopsy and biochemical evaluation.

On physical examination, when palpable, $\mathrm{PC}$ tend to consist of soft, mobile, non-tender masses, usually located in the lower part of the neck. ${ }^{33}$ US may reveal a non-specific cystic structure and cannot confirm whether the cyst arises from the parathyroid or the thyroid tissue. Nevertheless, a neck US performed by a specialist could be considered a valuable diagnostic tool in differentiating a PC from thyroid or other cystic masses..$^{34}$ Radio-nucleotide scan usually reveals areas with decreased or no uptake, thus mimicking cold nodules. Tc-Sestamibi or Th-201-Tc scans provide equivocal results, even in cases of functioning PC. ${ }^{35}$ Computed tomography or magnetic resonance imaging can be useful in cases with substernal extension or when symptoms of compression occur, by defining the cystic nature of the mass, without accurately differentiating PC from other cystic masses in this region. ${ }^{36}$ NA biopsy remains a valuable diagnostic tool. Typical findings of a watery, colourless crystal clear fluid are suggestive of the diagnosis in the majority of nonfunctioning PC, although a coloured aspirate does not exclude the existence of a PC. ${ }^{37}$ In some cases of functioning PC, the aspirate may be yellow or brown due to a preexisting degenerated or infracted parathyroid adenoma containing hemosiderin. The diagnosis can be established by elevated levels of PTH in the aspirated fluid. ${ }^{38}$

Thyroid cysts usually yield a yellowish or bloody aspirate with high levels of $\mathrm{Tg}$ and undetectable levels of PTH,${ }^{39}$ whereas branchial cysts yield a yellowish and viscous aspirate. Nonfunctioning PC have cystic fluid 
PTH concentrations ranging from several hundred to over $400,000 \mathrm{pg} / \mathrm{ml}$ with normal serum PTH concentration. ${ }^{8}$ According to the above, the overactivity of a PC should be assessed by the calcium and PTH levels in the patient's serum and not by the aspirate's PTH levels. Most authors suggest the measurement of the intact PTH molecule in order to avoid false negative results when using N-terminal PTH assays. ${ }^{40-42}$ Parathyroid NA cytology findings often overlap with those observed from thyroid epithelium. In these cases, special cytologic features such as the absence of colloid and specific patterns of vascularization and granularity are highly indicative of a parathyroid origin tissue. These features in combination with elevated PTH levels in the fluid help the clinician to differentiate $\mathrm{PC}$ from thyroid carcinoma or adenoma. However, in some (rare) cases differential diagnosis is extremely difficult. ${ }^{43}$

On microscopic examination, true (nonfunctioning) PC are usually consist of a smooth inner surface wall with a paper-thin, tough membranous lining. A solitary layer of compressed cuboidal or columnar epithelial cells that stain positive for glucogen usually forms the cystic lining. ${ }^{43}$ If a PC is discovered in the operating room, it presents as a smooth, shiny, semitransparent thin cystic mass usually attached to the thyroid and it is easily dissected from the thyroid and the other surrounding tissues. ${ }^{44}$ The intraoperative rupture of the cyst is not uncommon and special techniques should be followed in order to avoid parathyromatosis. $^{5}$

\section{Treatment}

There are a lot of therapeutic approaches but the management of choice in uncomplicated nonfunctioning PC is percutaneous cyst aspiration. Other treatment options include injection of sclerosing agents and surgery. Clark was the first to describe aspiration alone as therapy for PC. ${ }^{44}$ In most cases, NA results in cyst regression. ${ }^{45}$ However, PC may recur after aspiration and, although repeated aspirations may be performed, the effectiveness of this approach is variable. ${ }^{46,47}$ In the case of recurrences, as in one of our cases (case 4), surgical management is the treatment of choice.

Surgical excision remains the treatment of choice in functioning PC, or nonfunctioning cysts present- ing with compressive symptoms or carcinomas. ${ }^{45,48,49}$ Minimally invasive surgery could be considered as a valid approach for parathyroid cystic lesions in specialized centers. ${ }^{15}$ Intraoperative measurements of PTH levels offer a useful tool in the evaluation of a successful operation outcome, but they can be misleading when rupture of the cyst occurs during surgery. Calcium levels should be monitored postoperatively since hypocalcaemia has been reported after the successful removal of predominantly larger hyperfunctioning cysts, as in our seventh case. ${ }^{5}$

Another alternative treatment could be the injection of sclerosing agents into the cyst (tetracycline solution or ethanol), especially in cases of recurrence. The use of sclerosing agents entails the risk of fibrosis and recurrent laryngeal nerve palsy, especially when the inferior parathyroid is involved, because of its proximity to the inferior laryngeal nerve..$^{50,51}$ The choice of treatment should be tailored to each patient taking into account the size of the cyst and the presenting clinical findings.

Our series appears to be one of the largest presented in the literature. We lay emphasis on the use of needle aspiration as a both diagnostic and therapeutic approach in the majority of cases. Previous elegant data in conjunction with our accumulated experience are integrated in Figure 3, where we propose a diagnostic algorithm to guide the diagnosis and management of PC.

\section{CONCLUSION}

$\mathrm{PC}$ are uncommon entities in clinical practice with a predominance in women, and the vast majority of them are nonfunctioning. Some cases produce local compressive symptoms, whereas functioning PC can be associated with primary hyperparathyroidism. The diagnosis can be established by finding elevated levels of PTH in the aspirated fluid, which in most cases of nonfunctioning cysts is a watery, colourless crystal clear fluid. Functioning PC are differentiated from nonfunctioning by observation of high serum levels of PTH and Ca. The treatment of choice in nonfuctioning cysts is aspiration, whereas surgical excision is recommended when relapse or compressive or infiltrative symptoms are present. Surgery is also the treatment of choice in functioning cysts. 


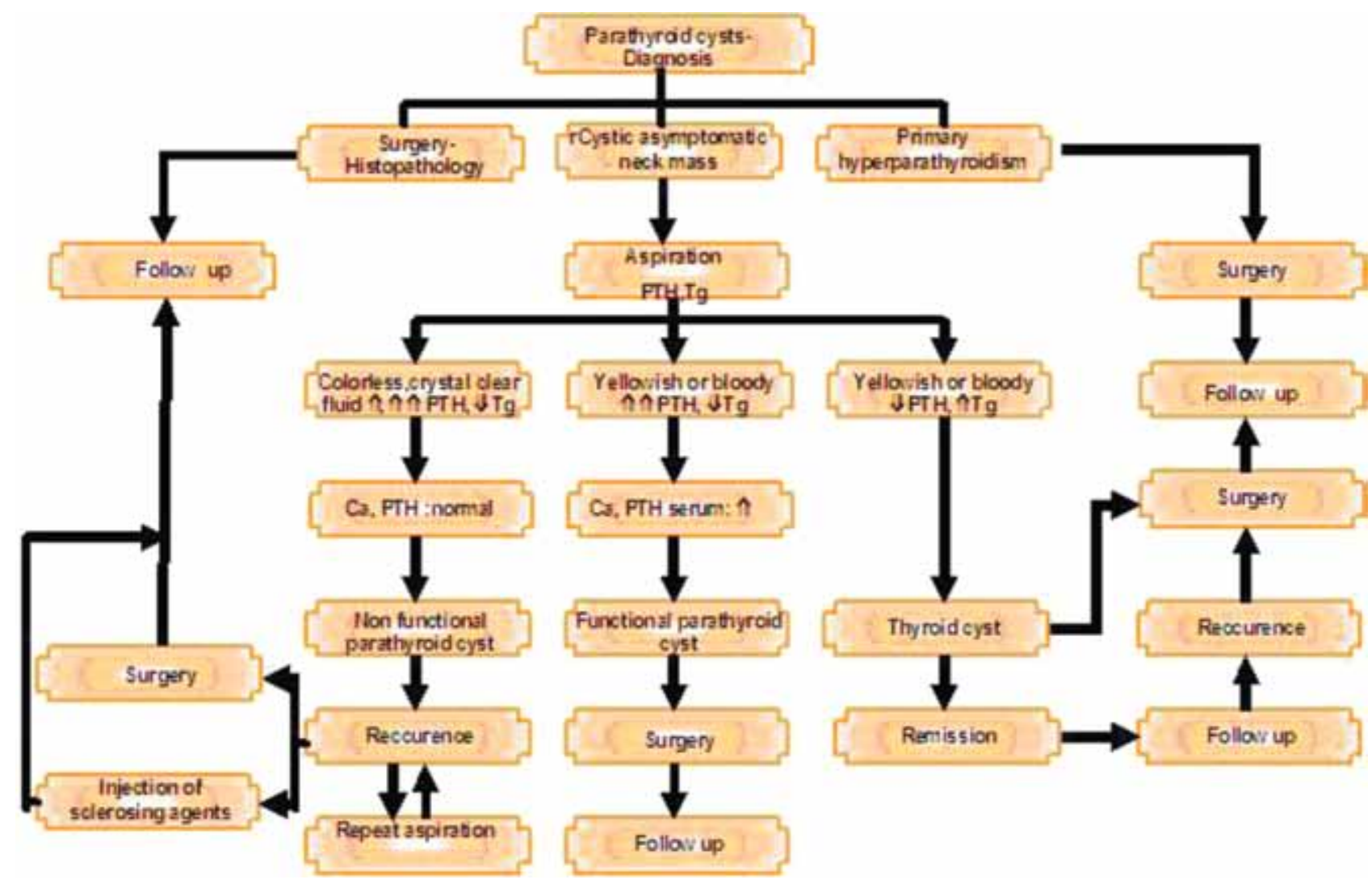

Figure 3. Proposed algorithm for the diagnostic and therapeutic work-up of patients with suspected parathyroid cysts.

\section{REFERENCES}

1. Sandstrom I, $1880 \mathrm{Om}$ en kortel hos mennishkan och atskilliga doggdjus. Ups Lakafor Forhandl 14: 441-471.

2. Goris D, 1905 Extirpation de trios lobules parathyroidens kystiques. Ann Soc Belge Chir 5: 394-400.

3. Alvi A, Myssiorek D, Wasserman P, 1996 Parathyroid cysts: current diagnostic and management principles. Head Neck 18: 370-373.

4. Braccini F, Epron JP, Roux C, et al, 2000 Essential parathyroid cysts: a misleading lesion. Rev Laryngol Otol Rhinol (Bord) 121: 165-168.

5. McCoy KL, Yim JH, Zuckerbraun BS, Ogilvie JB, Peel RL, Carty SE, 2009 Cystic parathyroid lesions: functional and nonfunctional parathyroid cysts. Arch Surg 144: 52-56.

6. Cappelli C, Rotondi M, Pirola I, et al, 2009 Prevalence of parathyroid cysts by neck ultrasound scan in unselected patients. J Endocrinol Invest 32: 357-359.

7. Mevio E, Gorini E, Sbrocca M, Artesi L, Mullace M, Lecce S, 2004 Parathyroid cysts: description of two cases and review of the literature. Acta Otorhinolaryngol Ital 24: 161-164.

8. Rangnekar N, Bailer WJ, Ghani A, Carbonell FA, Nowak M, 1996 Parathyroid cysts. Report of four cases and review of the literature. Int Surg 81: 412-414.
9. Wirowski D, Wicke C, Böhner H, et al, 2008 Presentation of 6 cases with parathyroid cysts and discussion of the literature. Exp Clin Endocrinol Diabetes 116: 501-506.

10. Ippolito G, Palazzo FF, Sebag F, Sierra M, De Micco C, Henry JF, 2006 A single-institution 25-year review of true parathyroid cysts. Langenbecks Arch Surg 391: 13-18.

11. Lydiatt DD, Byers RM, Khouri KG, Whitworth PW, Sellin RV, 1993 Functional parathyroid cyst and hypocalciuric hypercalcemia. Ear Nose Throat J 72: 142-144.

12. Entwistle JW, Pierce CV, Johnson DE, O’Donovan SC, Bagwell CE, Salzberg AM, 1994 Parathyroid cysts: report of the sixth and youngest pediatric case. J Pediatr Surg 29: 1528-1529.

13. McCluggage WG, Russell CF, Toner PG, 1995 Parathyroid cyst of the thymus. Thorax 50: 913-914.

14. Shields TW, Immerman SC, 1999 Mediastinal parathyroid cysts revisited. Ann Thorac Surg 67: 581-590.

15. Gamondes JP, Maret G, Berger G, Brune J, Joud R, 1978 Parathyroid adenoma of the upper mediastinum with blood-filled cyst causing dyspnoea. Nouv Presse Med 7: 4149.

16. Umemori Y, Makihara S, Kotani K, Washio K, 2002 Mediastinal parathyroid cyst with tracheal constriction. Jpn J Thorac Cardiovasc Surg 50: 85-87.

17. Sen P, Flower N, Papesch M, Davis A, Spedding AV, 
2000 A benign parathyroid cyst presenting with hoarse voice. J Laryngol Otol 114: 147-148.

18. Grey AB, Shaw JH, Anderson NE, Holdaway IM, 1993 Parathyroid cyst with recurrent vocal cord paresis. Aust N Z J Surg 63: 561-562.

19. Coelho DH, Boey HP, 2006 Bening parathyroid cyst causing vocal fold paralysis: a case report and review of the literature. Head Neck 28: 564-566.

20. Gattas N, Solt I, Loberant N, Hazani E, Rimon D, 2007 Parathyroid cyst associated with acute respiratory failure and jugular vein thrombosis. Harefuah 146: 599-601, 646.

21. Capezzone M, Morabito E, Bellitti P, Giannasio P, de Santis D, Bruno R, 2007 Ectopic intrathyroidal nonfunctioning parathyroid cyst. Endocr Pract 13: 56-58.

22. Rickels MR, Langer JE, Mandel SJ, 2004 Hyperfunctioning intrathyroidal parathyroid cyst. J Clin Endocrinol Metab 89: 1051-1052.

23. Halenka M, Frysak Z, Koranda P, Kucerova L, 2008 Cystic parathyroid adenoma within a multinodular goiter: a rare cause of primary hyperparathyroidism. J Clin Ultrasound 36: 243-246.

24. Cao H, Lai CK, Head CS, Sercarz JA, 2008 Cystic parathyroid presenting as an apparent thyroid goiter. Eur Arch Otorhinolaryngol 265: 1285-1288.

25. McKay GD, Ng TH, Morgan GJ, Chen RC, 2007 Giant functioning parathyroid cyst presenting as a retrosternal goiter. ANZ J Surg 77: 297-304.

26. Mitmaker B, Lerman S, Lamoureux E, Begin L, 1991 Parathyroid cyst: diagnosis and treatment of an unusual surgical problem. Can J Surg 34: 59-61.

27. Gurbuz AT, Peetz ME, 1996 Giant mediastinal parathyroid cyst: an unusual cause of hypercalcemic crisis-case report and review of the literature. Surgery 120: 795-800.

28. Guvendik L, Oo LK, Roy S, Donaldson LA, Kennedy DD, 1993 Management of a mediastinal cyst causing hyperparathyroidism and tracheal obstruction. Ann Thorac Surg 55: 167-168.

29. Khan A, Khan Y, Raza S, Akbar G, Khan M, Diwan N, Rizvi W, 2012 Functional parathyroid cyst: a rare cause of malignant hypercalcemia with primary hyperparathyroidism-a case report and review of the literature. Case Rep Med 2012: 851941.

30. Marsot-Dupuch K, Levret N, Pharaboz C, et al, 1995 Congenital neck masses. Embryonic origin and diagnosis. Report of the CIREOL. J Radiol 76: 405-415.

31. Lima AC, Fregnani ER, Silva-Sousa YT, da Cruz Perez DE, 2012 Parathyroid hormone/parathyroid hormonerelated peptide receptor 1 expression in odontogenic cystic lesions. Int Endod J 45: 209-214.

32. 32. Nonaka D. 2011 Study of parathyroid transcription factor Gcm 2 expression in parathyroid lesions Am J Surg Pathol 35: 145-151.

33. 33. Haid SP, Method HL, Beal JM, 1967 Parathyroid cysts. Arch Surg 94: 421-426.

34. 34. Cappelli C, Gandossi E, Pirola I, De Martino E, Delbarba A, Maurizio C, 2007 Parathyroid cyst: often mistaken for a thyroid cyst. World J Surg 31: 2269.

35. Gough IR, 1999 Parathyroid cysts. Aust N Z J Surg 69: 404-406.

36. Kato H, Kanematsu M, Kiryu T, et al, 2008 Nonfunctional mediastinal parathyroid cyst: imaging findings in two cases. Clin Imaging 32: 310-313.

37. Layfield LJ, 1991 Fine needle aspiration cytology of cystic parathyroid lesions. A cytomorphologic overlap with cystic lesions of the thyroid. Acta Cytol 35: 447-450.

38. Ihm PS, Dray T, Sofferman RA, Nathan M, Hardin NJ, 2001 Parathyroid cysts: diagnosis and management. Laryngoscope 111: 1576-1578.

39. Pacini F, Antonelli A, Lari R, Gasperini L, Baschieri A, Pinchera A, 1985 Unsuspected parathyroid cysts diagnosed by measurement of thyroglobulin and parathyroid hormone concentrations in fluid aspirates. Ann Intern Med 102: 793-794.

40. Silverman JF, Khazanie PG, Norris HT, Fore WW, 1986 Parathyroid hormone (PTH) assay of parathyroid cysts examined by fine-needle aspiration biopsy. Am J Clin Pathol 86: 776-780.

41. Nozeran S, Duquenne M, Guyetant S, et al, 2000 Diagnosis of parathyroid cysts: value of parathyroid hormone level in puncture fluid. Presse Med 29: 939-941.

42. Kasperk C, Buhr H, Raue F, Hofmann W, Lorenz D, Ziegler R, 1992 Endocrinously active parathyroid cysts. Their diagnosis by the determination of intact parathormone in the cyst fluid. Dtsch Med Wochenschr 117: 1093-1096.

43. Lerud KS, Tabbara SO, DelVecchio DM, Frost AR, 1996 Cytomorphology of cystic parathyroid lesions: report of four cases evaluated preoperatively by fine-needle aspiration. Diagn Cytopathol 15: 306-311.

44. Clark OH, 1978 Parathyroid cysts. Am J Surg 135: 395-402.

45. Prinz RA, Peters JR, Kane JM, Wood J, 1990 Needle aspiration of nonfunctioning parathyroid cysts. Am Surg 56: 420-422.

46. Kodama T, Obara T, Fujimoto Y, Ito Y, Yashiro T, Hirayama A, 1987 Eleven cases of nonfunctioning parathyroid cyst-significance of needle aspiration in diagnosis and management. Endocrinol Jpn 34: 769-777.

47. Clark OH, Okerlund MD, Cavalieri RR, Greenspan FS, 1979 Diagnosis and treatment of thyroid, parathyroid, and thyroglossal duct cysts. J Clin Endocrinol Metab 48: 983-988.

48. Wright JG, Brangle RW, 1985 Carcinoma in a parathyroid cyst. IMJ III Med J 168: 98-100.

49. Pirundini P, Zarif A, Wihbey JG, 1998 A rare manifestation of parathyroid carcinoma presenting as a cystic neck mass. Conn Med 62: 195-197.

50. Sanchez A, Carretto H, 1993 Treatment of a nonfunctioning parathyroid cyst with tetracycline injection. Head Neck 15: 263-265.

51. Akel M, Salti I, Azar ST, 1999 Successful treatment of parathyroid cyst using ethanol sclerotherapy. Am J Mad Sei 317: 50-52. 